\title{
Comprehensive Evaluation of Agricultural Modernization Development Level in Gansu Province
}

\author{
Wang Cuiyun \\ College of Geography and Environmental Engineering, Lanzhou City University, Lanzhou, 730070, Gansu, China
}

\begin{abstract}
The agricultural foundation is weak in Gansu Province. In recent years, with the implementation of various policies to benefit farmers, agriculture and rural areas have undergone tremendous changes and made remarkable achievements. However, there are still many problems, and the gap is still expanding compared with the whole country. In order to further improve agricultural modernization in Gansu Province, this paper uses the entropy method to evaluate and compare the development of agricultural modernization in Gansu Province in the past 10 years. Through the corresponding countermeasures, it provides a theoretical basis for Gansu Province to formulate agricultural modernization development plans and policy measures.
\end{abstract}

\section{Introduction}

Since the reform and opening up, especially after the twelfth five-year plan, with the implementation of 365 modern agricultural development plan in Gansu Province, it has made great achievements in agricultural development, farmers' income has increased rapidly, and agricultural modernization has steadily improved. However, due to the weak basic agricultural conditions, outdated facilities and equipment, lagging scientific and technological progress, which fail to keep up with the development of agricultural modernization, agriculture is still the short board in integrating the development of industrialization, IT application, urbanization and agricultural modernization [1]. This paper uses the entropy method to evaluate and compare the development of agricultural modernization in Gansu Province in the past 10 years, and proposes corresponding countermeasures to provide a theoretical basis for Gansu Province to formulate agricultural modernization development plans and policy measures.

\section{Research Methods and Data Processing}

\subsection{Establishment of indicator system}

Agricultural modernization is the only way to transform agriculture from traditional to modern, which is longterm and arduous. In this process, it is necessary to organize agricultural activities with modern industry, modern science and modern management methods, and gradually realize the modernization of agricultural production, agricultural assembly and rural life.
The selection of agricultural modernization level evaluation index system needs to follow the principles of systematicity, accuracy, representativeness and operability. Based on the existing research results of agricultural modernization development level, according to the actual situation of Gansu Province, 14 indicators are selected from three aspects, including agricultural production modernization, agricultural equipment modernization and rural life modernization [2][3][4], reflecting the level of agricultural modernization in Gansu Province (see Table 1).

\subsection{Determination of indicator weights}

In this paper, the entropy method of objective assignment is used to determine the weight. According to the variation of the observation values of each index, the entropy value of each index is calculated by using information entropy, and the weight of each index is corrected by the entropy value, so that the objective index weight is obtained ${ }^{[5][6]}$. Specific steps are as follows:

\subsubsection{Non-negative processing of data}

Since the entropy method calculates the ratio of the value of one indicator to the sum of the same index in each scheme, there is no dimension effect and no standardization is needed. If there is a negative number in the data, non-negative processing of the data is needed. In addition, in order to avoid the meaninglessness of the logarithm when entropy is sought, data translation is required:

For positive indicators: $\mathrm{X}_{\mathrm{ij}}=\frac{\mathrm{X}_{\mathrm{ij}}-\min \left(\mathrm{X}_{\mathrm{ij}}\right)}{\max \left(\mathrm{X}_{\mathrm{ij}}\right)-\min \left(\mathrm{X}_{\mathrm{ij}}\right)}+$ $1 \quad(i=1 、 2 \ldots m ; j=1 、 2 \ldots n)$ 
For negative indicators: $X_{i j}=\frac{\max \left(X_{i j}\right)-X_{i j}}{\max \left(X_{i j}\right)-\min \left(X_{i j}\right)}+$ $1 \quad(i=1,2 \ldots m ; j=1,2 \ldots n)$

\subsubsection{Proportion calculation of the $i$-th program under the index of index $j$}

$$
P_{i j}=\frac{X_{i j}}{\sum_{i=1}^{m} X_{i j}} \quad(i=1,2 \ldots m ; j=1 、 2 \ldots n)
$$

\subsubsection{Entropy calculation of the $j$-th indicator}

$$
\mathrm{e}_{\mathrm{j}}=-\mathrm{K} \times \sum_{\mathrm{i}=1}^{\mathrm{n}} \ln \left(\mathrm{P}_{\mathrm{ij}}\right)
$$

Where $K>0$, $\ln$ is the natural logarithm, $e_{j} \geq 0$. The constant $\mathrm{K}$ in the equation is related to sample $\mathrm{n}$, and generally let $K=1 / \ln (n)$.

\subsubsection{Calculation of the difference coefficient of the $j$-th indicator}

For the $\mathrm{j}$-th index, the greater the difference in the index value $\mathrm{X}_{\mathrm{ij}}$, the greater the effect on the scheme evaluation, and the smaller the entropy value. $g_{j}=1-e_{j}$, where the larger the $\mathrm{g}_{\mathrm{j}}$ is, the more important the indicator become.

\subsubsection{Calculation of weight value of each index}

$$
W_{j}=\frac{g_{j}}{\sum_{j=1}^{n} g_{j}} \quad(j=1,2 \ldots n)
$$

Through this method, 14 indicators and 140 raw data [7] for evaluation of agricultural modernization development level in Gansu Province in 2008-2017 are calculated, and

\begin{tabular}{|c|c|c|c|c|}
\hline $\begin{array}{l}\text { The first grade } \\
\text { indicators }\end{array}$ & $\begin{array}{l}\text { The second grade } \\
\text { indicators }\end{array}$ & No. & The third grade indicators & weight \\
\hline \multirow{14}{*}{$\begin{array}{c}\text { agricultural } \\
\text { modernization } \\
\text { development } \\
\text { level }\end{array}$} & \multirow{5}{*}{$\begin{array}{l}\text { agricultural } \\
\text { production } \\
\text { modernization }\end{array}$} & 1 & $\begin{array}{c}\text { the per capita output value of agriculture, forestry, animal husbandry } \\
\text { and fishery (yuan/per person) }\end{array}$ & 0.0424 \\
\hline & & 2 & per capita food production $(\mathrm{kg} /$ per person $)$ & 0.0746 \\
\hline & & 3 & per capita meat production $(\mathrm{kg} /$ per person $)$ & 0.0665 \\
\hline & & 4 & $\begin{array}{l}\text { total output value of agriculture, forestry, animal husbandry and fishery } \\
\text { per unit area (ten thousand yuan/ha.) }\end{array}$ & 0.0473 \\
\hline & & 5 & grain yield per unit area $(\mathrm{kg} / \mathrm{ha})$. & 0.1036 \\
\hline & \multirow{5}{*}{$\begin{array}{c}\text { agricultural } \\
\text { equipment } \\
\text { modernization }\end{array}$} & 6 & agricultural mechanization ( $\mathrm{kwh} / \mathrm{ha}$. $)$ & 0.0522 \\
\hline & & 7 & agricultural water conservancy $(\%)$ & 0.2568 \\
\hline & & 8 & agricultural chemicalization (ton/ ha.) & 0.0933 \\
\hline & & 9 & agricultural electrification（million kwh /per year） & 0.0494 \\
\hline & & 10 & agricultural capital investment (ten thousand per yuan / per year) & 0.0374 \\
\hline & \multirow{4}{*}{$\begin{array}{c}\text { rural life } \\
\text { modernization }\end{array}$} & 11 & rural per capita disposable income (yuan/per year) & 0.0351 \\
\hline & & 12 & Engel coefficient of rural residents（\%) & 0.0533 \\
\hline & & 13 & rural per capita living area（m2/ per person $)$ & 0.0540 \\
\hline & & 14 & rural medical assistance (ten thousand person) & 0.0341 \\
\hline
\end{tabular}
the weight values of each indicator are shown in Table 1.

Table 1 Evaluation index system and indicator weight value of agricultural modernization development level in Gansu Province

From the ranking of the weights of the 14 indicators, the top three are agricultural water conservancy (effective irrigation rate of farmland), grain yield per unit area and agricultural chemicalization (effective fertilizer application per unit of cultivated land area), indicating between 2008 and 2017, these three indicators were the most important factors affecting the development of agricultural modernization in Gansu Province. The weights of other indicators are from high to low: per capita food production, per capita meat production, rural per capita living area, Engel coefficient of rural residents, agricultural mechanization, agricultural electrification, total output value of agriculture, forestry, animal husbandry and fishery per unit area, the per capita output value of agriculture, forestry, animal husbandry and fishery, agricultural capital investment, rural per capita disposable income and rural medical assistance.

\section{Evaluation of Agricultural Modernization Development in Gansu Province}

The evaluation equation of the level of agricultural modernization is:

$$
\mathrm{S}_{\mathrm{i}}=\sum_{\mathrm{j}=1}^{\mathrm{n}} \mathrm{W}_{\mathrm{j}} \times \mathrm{P}_{\mathrm{ij}} \quad(\mathrm{i}=1,2 \ldots \mathrm{m} ; \mathrm{j}=1,2 \ldots \mathrm{n})
$$

The pre-processed value of the original data and the calculated weight value are calculated according to the above equation, and the values of the second-level indicator and the first-level indicator are obtained, which are the value of modernization of agricultural production, agricultural equipment and rural life, as well as comprehensive development of agricultural modernization. The calculation results are shown in Table 2 and Figure 1. 
Table 2 Agricultural modernization development level, subsystem score and its relative growth rate in Gansu Province

\begin{tabular}{|c|c|c|c|c|c|c|c|c|}
\hline \multirow{2}{*}{ year } & \multicolumn{2}{|c|}{$\begin{array}{l}\text { Agricultural modernization } \\
\text { development level }\end{array}$} & \multicolumn{2}{|c|}{$\begin{array}{l}\text { agricultural production } \\
\text { modernization }\end{array}$} & \multicolumn{2}{|c|}{$\begin{array}{l}\text { agricultural equipment } \\
\text { modernization }\end{array}$} & \multicolumn{2}{|c|}{ rural life modernization } \\
\hline & score & growth rate & score & growth rate & score & growth rate & score & growth rate \\
\hline 2008 & 0.7874 & & 0.1466 & & 0.2779 & & 0.3629 & \\
\hline 2009 & 0.8084 & 0.0266 & 0.1523 & 0.0388 & 0.2804 & 0.0091 & 0.3756 & 0.0350 \\
\hline 2010 & 0.8363 & 0.0345 & 0.1691 & 0.1100 & 0.2906 & 0.0363 & 0.3766 & 0.0026 \\
\hline 2011 & 0.8616 & 0.0303 & 0.1811 & 0.0711 & 0.2957 & 0.0177 & 0.3848 & 0.0218 \\
\hline 2012 & 0.8928 & 0.0361 & 0.1996 & 0.1024 & 0.3025 & 0.0229 & 0.3906 & 0.0151 \\
\hline 2013 & 0.9165 & 0.0266 & 0.2114 & 0.0589 & 0.3085 & 0.0196 & 0.3966 & 0.0154 \\
\hline 2014 & 0.9398 & 0.0255 & 0.2213 & 0.0470 & 0.3132 & 0.0154 & 0.4053 & 0.0218 \\
\hline 2015 & 0.9677 & 0.0297 & 0.2292 & 0.0355 & 0.3243 & 0.0354 & 0.4142 & 0.0220 \\
\hline 2016 & 0.9733 & 0.0058 & 0.2313 & 0.0090 & 0.3225 & -0.0056 & 0.4195 & 0.0129 \\
\hline 2017 & 0.9665 & -0.0069 & 0.2170 & -0.0618 & 0.3246 & 0.0066 & 0.4249 & 0.0129 \\
\hline
\end{tabular}

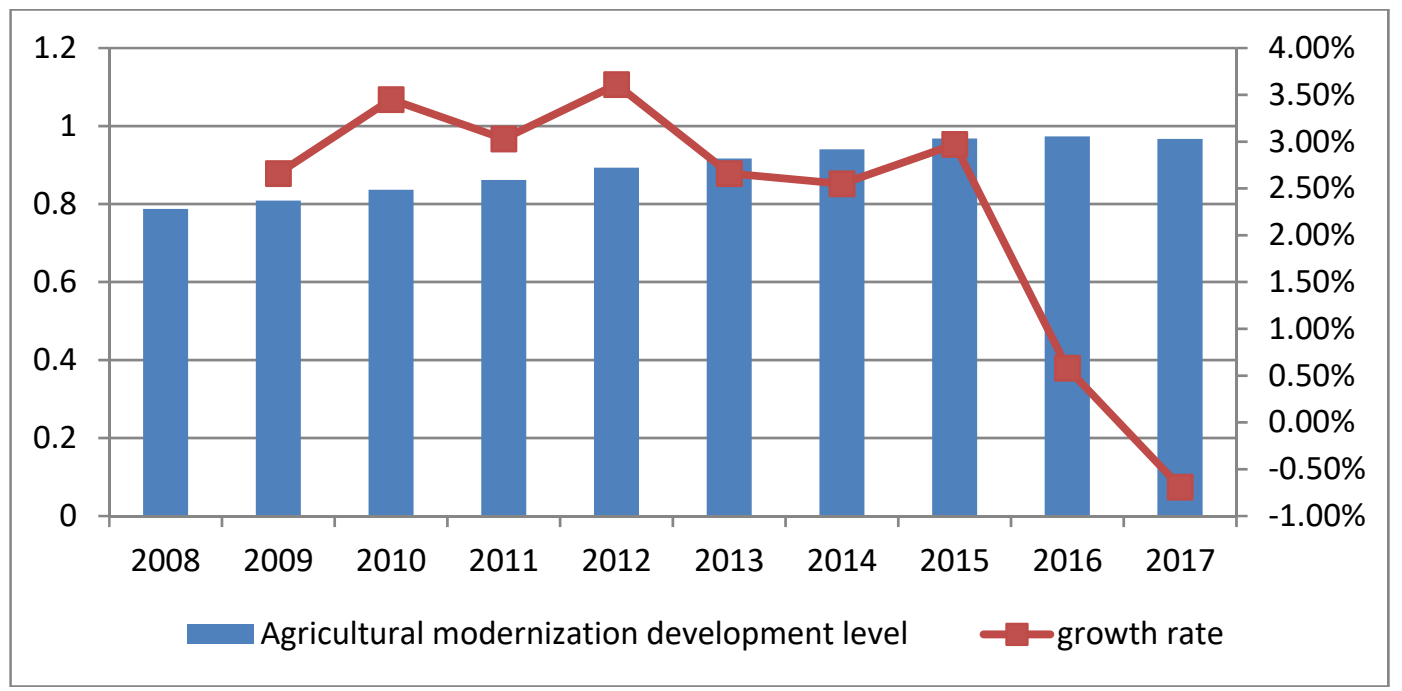

Figure 1 Trends in agricultural modernization development and growth rate in Gansu Province from 2008 to 2017

It can be seen from Table 2 and Figure 1 that the level of agricultural modernization development in Gansu Province increased from 0.7874 in 2008 to 0.9733 in 2016. After a slight decline in 2017, the score was 0.9665 , and the overall trend is on the rise. It shows that in the past 10 years, the agricultural modernization in Gansu Province has achieved remarkable results, and has been continuously improved. This results from the fact that Gansu Province has been closely focusing on the central task of increasing production and efficiency, and increasing farmers' income, and has earnestly implemented the policy of strengthening agriculture and benefiting farmers, so that the agriculture has maintained a good momentum of development. Especially during the twelfth five-year plan, with the implementation of the 365 modern agricultural development plans, the agricultural economic benefits have improved significantly.

However, its growth rate has changed by a large margin. The highest growth rate is from 2010 to 2012, and the growth rate is higher than $3 \%$. Among them, the growth rate in 2012 was the highest, reaching 3.61\%, followed by $2010,3.45 \%$, and slightly lower in 2011 , $3.03 \%$. The high growth rate of these three years is related to the six major actions initiated by Gansu Province in 2008 to promote agriculture and increase income, and the development of industries with local advantages. The six major actions have led to a rapid increase in farmers' income. For the first time in 20092010 , the growth rate exceeds that of urban residents, and the income structure has undergone huge changes. At the same time, the development of industries with local advantages is contributed to the cultivation of more than 30 million mu of advantageous crops in Gansu Province, accounting for more than half of the crop planting area, providing operational income for about two-thirds of the farmers' families ${ }^{[7]}$. The growth rate has declined since 2013, and the growth rate from 2013 to 2015 has remained above $2.5 \%$, at $2.66 \%, 2.55 \%$ and $2.97 \%$ respectively. It was the lowest in 2016 and 2017, with a growth rate of only $0.58 \%$ in 2016 . For the first time in 2017 , there was a negative growth with a growth 
rate of $-0.69 \%$. The reason is related to China's economic entry into the new normal and the weak agricultural basic conditions in Gansu Province.

\section{Analysis of Agricultural Modernization Subsystem in Gansu}

\subsection{Analysis of subsystem of agricultural production modernization}

In the past 10 years, the modernization of agricultural production in Gansu Province has been greatly improved (see Table 2). The evaluation value of the agricultural production modernization subsystem increased from 0.1466 in 2008 to 0.2313 in 2016, and decreased in 2017 to 0.2170 . From the perspective of the growth process, agricultural modernization shows an upward trend year by year, but the growth rate is not stable. From 2009 to 2012, the fluctuations were large. In 2010 and 2012, the growth rate was relatively fast. In 2010, it reached a maximum value, with a growth rate of $11 \%$, followed by 2012 with a growth rate of $10.24 \%$. Then it was slow in 2009 and 2011. Since 2013, the growth rate has gradually slowed down, with the first negative growth in 2017 , with a rate of $-6.18 \%$.

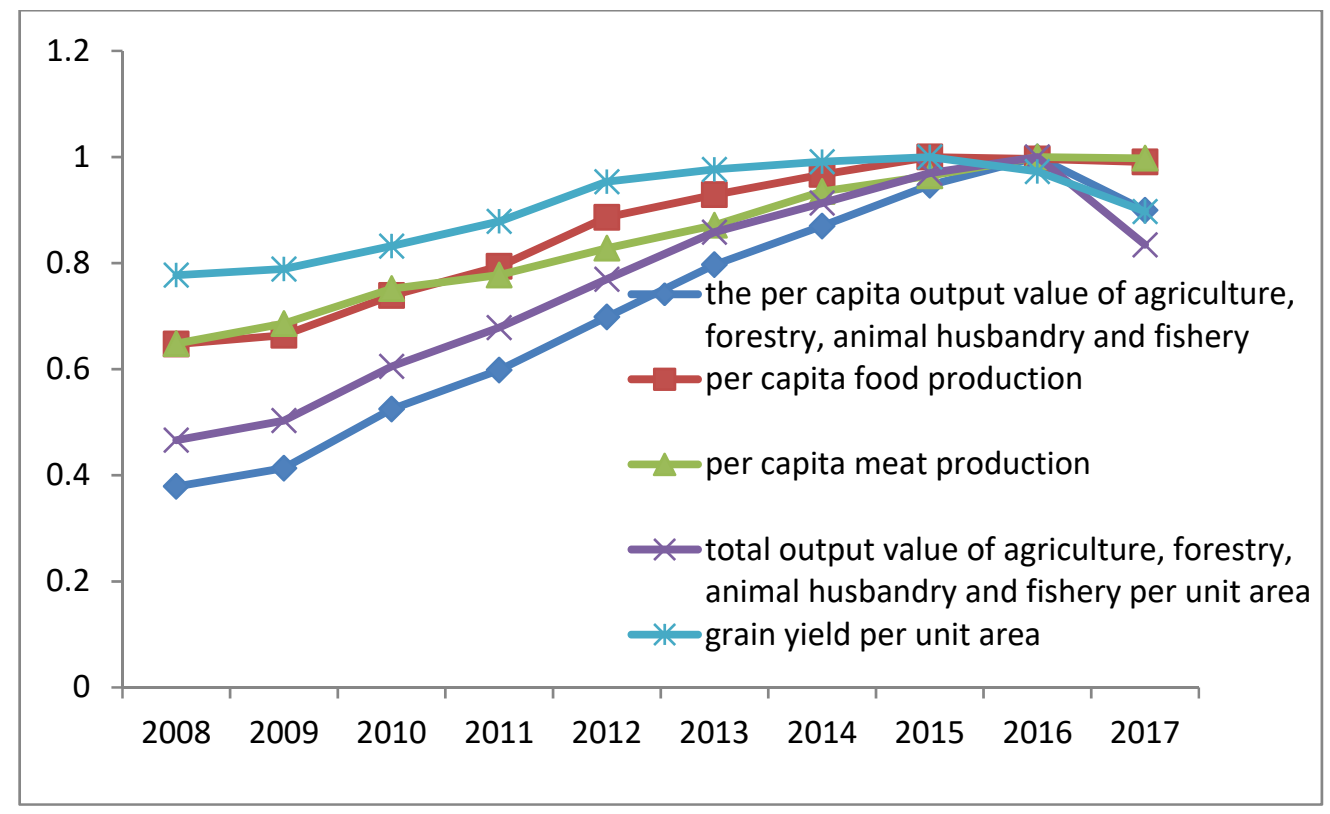

Figure 2 Trends in the evaluation of agricultural production subsystems in Gansu from 2008 to 2017

From the perspective of changes in specific indicators (see Figure 2), the five indicators used for the evaluation of agricultural production subsystems have been growing in the past 10 years. The per capita output of agriculture, forestry, animal husbandry and fishery increases the fastest, followed by the output value of agriculture, forestry, animal husbandry and fishery per unit area, indicating that the output value is the most important factor in upgrading agricultural production modernization subsystem. In 2008-2011, the per capita grain output and meat production changed more closely. Since 2012, the per capita grain output has increased faster than meat production. The change in grain output per unit area is relatively stable. The growth rate was relatively fast between 2008 and 2012, and then gradually slowed down.

The increase in the output value of agriculture, forestry, animal husbandry and fishery fully demonstrates that the agricultural product commodity rate in Gansu Province is remarkably improved, the agricultural industrial chain is gradually extended, and the farmers' awareness of commodity and quality is significantly enhanced. In recent years, sales of high- quality miscellaneous grains, organic fruits and vegetables, plateau summer vegetables and other products in Gansu have gradually increased in the domestic market. Fresh apples, apple juice and other products become the main products of foreign trade exports, helping increasing the export volume. In the meanwhile, industrial structure dominated by agriculture also undergoes corresponding changes, and the proportion of forest, animal husbandry, and side occupations increases accordingly.

\subsection{Analysis of agricultural equipment modernization subsystem}

As is seen from Table 2, the agricultural water modernization in Gansu Province has risen steadily in the past 10 years, from 0.2779 in 2008 to 0.3246 in 2017 . The growth process is relatively stable, and the rate is basically maintained at around $2.0 \%$. Two high values occurred in 2010 and 2015, with increases of $3.63 \%$ and $3.54 \%$, while two low values occurred in 2009 and 2016 , with increases of $0.91 \%$ and $-0.56 \%$. 


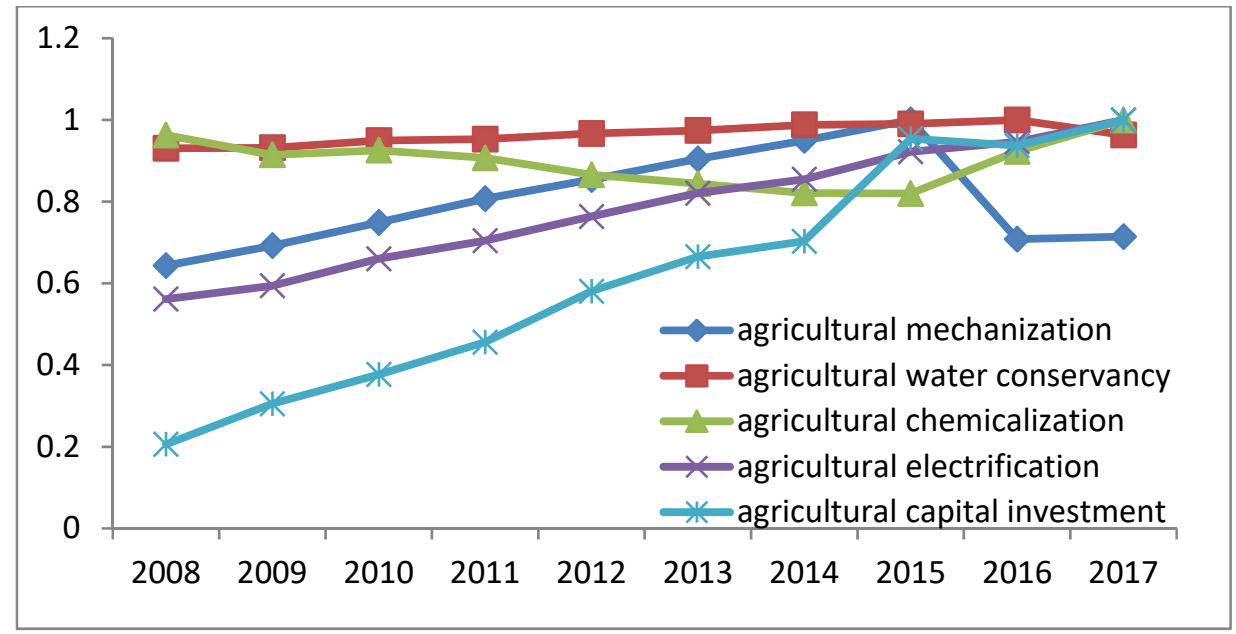

Figure 3 Trends in the evaluation of agricultural assembly subsystems in Gansu Province from 2008 to 2017

From the change of specific indicators (see Figure 3), among the five indicators of the agricultural equipment subsystem, the fastest growth and the largest increase fall on the agricultural capital investment, which increased from 10.733 billion yuan in 2008 to 52.079 billion yuan in 2017. It fully shows that the government attach great importance to agriculture and rural areas. Secondly, the per capita electricity consumption in rural areas and the total power of agricultural machinery per hectare increase significantly. The increase in the total number of agricultural machinery powers is attributed to the agricultural machinery purchase subsidy policy, which includes self-purchasing, fixed subsidies, county-level settlement and direct subsidies to cards, promoted by the Gansu provincial government. The policy enhances the equipment and operational capacity of cooperatives by arranging special funds, subsidizing the purchase of various types of agricultural machinery, and supporting agricultural machinery cooperatives. What's more, the effective irrigation rate remains basically the same, indicating that some farmland cannot be irrigated due to restricted water resources, and agricultural irrigation has less room for improvement in terms of quantity. The amount of effective chemical fertilizer applied per unit of cultivated land decreases slightly, because most farmers fail to rationally fertilize according to the growth characteristics of different crops, but blindly apply too much nitrogen, phosphate and potash. With the development of green agriculture, demand for pollutionfree food and vegetables is increasing, and the application rate of chemical fertilizers is controlled at a reasonable level.

\subsection{Analysis of rural life modernization subsystem}

It can be seen from Table 2 that modernization of rural life in Gansu has increased continuously in the past 10 years, from 0.3629 in 2008 to 0.4249 in 2017, which is the fastest growing among the three subsystems. However, the change in growth rate is not stable, and the maximum value appeared in 2009 with a rate of $3.5 \%$. Followed by 2015,2011 and 2014, the growth rate in 2015 was $2.2 \%$, and both in 2011 and 2014 were $2.18 \%$. The year with the lowest growth rate was in 2010, with a $\mathrm{h}$ rate of only $0.26 \%$.

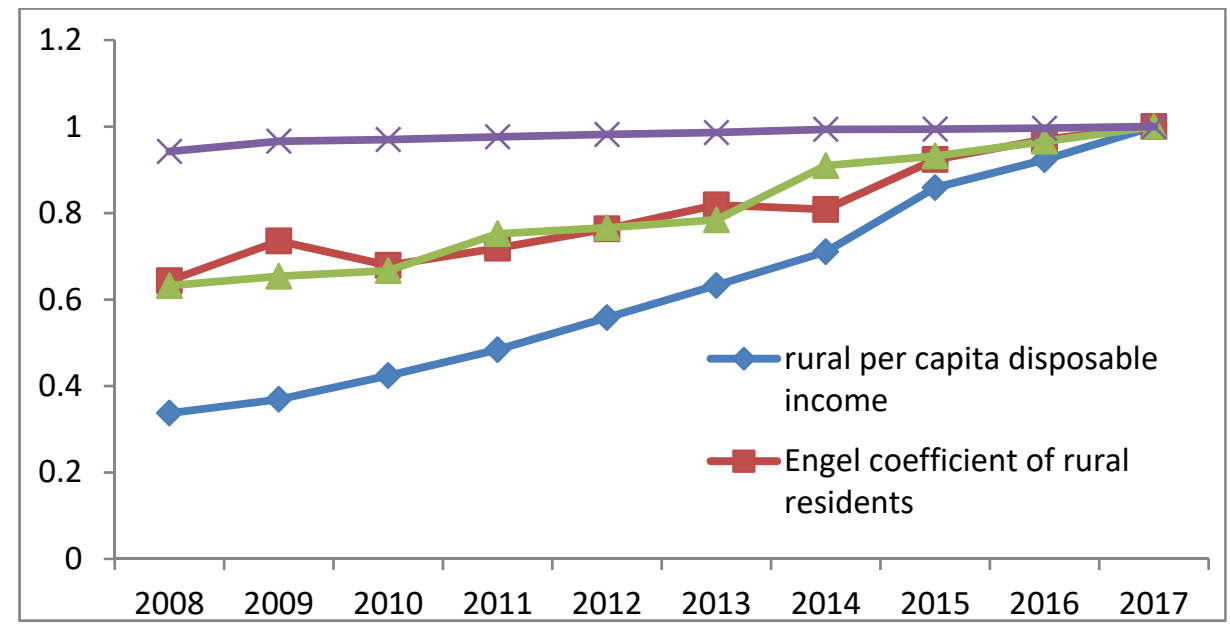

Figure 4 Trends in the evaluation of rural life subsystems in Gansu Province from 2008 to 2017 
As shown in the changes in the specific indicators in Figure 4, four indicators for evaluating the rural life subsystem are rising, and the faster one is per capita disposable income of rural resident, which is proven to be a greater contribution rate to the modernization of rural life subsystems. Although the Engel coefficient of rural residents and the growth rate of rural per capita living area are lower than the per capita disposable income of rural resident, they also express an increasing trend in the past 10 years. Besides, the change in rural medical assistance is relatively stable. All of these represent that the Gansu government's efforts in various policies for strengthening agriculture and benefiting farmers eventually have paid off, including continually growing incomes in the past 10 years, improving life quality and rural infrastructure, and narrowing the income gap between urban and rural residents. As incomes increase, the living conditions of farmers continue to improve, and the proportion of food expenditures to personal consumption continues to decline.

\section{Conclusion}

In the past 10 years, the agricultural modernization in Gansu Province has achieved remarkable results. Although the growth rate has not changed very stably, still agricultural modernization generally shows an increasing trend. During this process, the rapid development of modernization of agricultural production and rural life has led to a small increase in the modernization of agricultural equipment. Consequently, the evolution of these three subsystems varies.

\section{Sponsored Projects:}

Gansu Provincial Philosophy and Social Science Planning Project "Gansu Province Agricultural Modernization Development Research (YB111)"

\section{About the author:}

Wang Cuiyun(1978-), female, from Ningwu, Shanxi Province, associate professor. Research direction: agricultural economy and rural environment

\section{References:}

1. Development Planning on the agricultural and rural economic for the thirteen five-year plan[R], The Development and Reform Commission of Gansu province.

2. Ai Hongjuan, Jiang Heping, Studies on Evaluating Agricultural Development Level in Xinjiang Based on Factor Analysis Method, Journal of Agricultural Science and Technology[J], 2015, 17(4) : $157-$ 164.

3. Fan Kuangsheng, Promoting Measures and Comprehensive Evaluation of the Agricultural Modernization in Henan Province[J], Hubei Agricultural Sciences, 2015, 54( 1) : 241 -244.

4. Zhang Meng, Yan Yuke, Zhang Weikun, Policy Suggestion and Measurement of Agricultural Modernization in Zhuhai City, Resource Development \& Market[J], 2017, 33 (3) :295300.

5. Ying Shouying, Liu Jinyang, The Evaluation on the Level of Agricultural Modernization Based on the Entropy and Weight in Sichuang[J],Rural Economy and Science-Technology, 2018, 29 (3) :168-171.

6. Chen Xiao, Comprehensive Evaluation on the Level of Agricultural Modernization in Nanjing[J], Cooperative Economy \& Science, 2017 (4) :4-6.

7. Development Planning on the agricultural and rural economic for the twelve five-year plan[R], The Development and Reform Commission of Gansu province. 